\title{
The effect of oral habits in the oral cavity of children and its treatment
}

\author{
Meirina Gartika \\ Department of Pediatric Dentistry Faculty of Dentistry Universitas Padjadjaran
}

\begin{abstract}
Oral habits include habit which are continuously done and has the potential to cause defects on teeth and perioral tissues. Some of the oral habits are finger/thumb sucking, lip sucking/biting, nail biting, bruxism, abnormal swallowing and mouth breathing. The etiology of oral habits includes disharmonious relationship between parents and children, dissatisfaction in oral phase, premature weaning, emotional disturbance, anomaly, and diseases. Oral habits will influence the development of occlusion and perioral structures in children in the growing and development process. The treatment of oral habits can be done with or without appliances. The non-appliance treatment consists of psychological approach, medical approach and myofunctional therapy while the appliance treatment will include the use of orthodontic appliances.
\end{abstract}

Key words: Oral habits, oral cavity

\section{INTRODUCTION}

Acomplete family means a complete familial structure, i.e. the presence of a father, mother and children. However, not all children are raised in an ideal family. They maybe raised in a complete family but with a disharmonious relationship between father and mother or between parents and children. Children who receive bad treatment from the family, who do not receive enough love from the parents, who experience emotional disturbance and who are often deprived of food may develop oral habits. ${ }^{1}$ Salzmann ${ }^{2}$ in his study reported factors such as fatigue, boredom, hunger, being scolded and punished as factors that may lead to one or more oral habits.

The oral habit that has been developed since a baby is still in the mother's womb is the thumb sucking reflex. This is due to the developed neuromuscular functions. ${ }^{3}$ The oral habit may continue to 3-4 years and will stop automatically. However, if this habit continues, it shows an emotional disturbance in the child. ${ }^{4}$

Oral habits may affect masticatory functions, respiration, speech and esthetics. ${ }^{5}$ A study performed. ${ }^{6}$ Shows that schoolchildren who have a oral habit, especially thumb sucking, significantly show less intelligence and eagerness to make friends. ${ }^{6} \mathrm{~A}$ study done, shows that from 693 children who have thumb sucking habit, $60 \%$ are able to reduce the habit by the age of around two years and most of the children in this group developed a normal occlusion. ${ }^{4}$ Meanwhile, the children who continue the habit exceeding the age ${ }^{4}$ show several types of malocclusion with most of them experiencing Angle Class II malocclusion. ${ }^{3}$ 


\section{Oral habit development}

Habit is defined in Dorland dictionary. ${ }^{7}$ as something that is fixed and constant that shows repetitive actions. The normal habits that are parts of orocraniofacial functions have important roles in normal craniofacial growth and occlusal physiology. On the contrary, an abnormal habit can cause disorders in the dentocraniofacial growth pattern in children. ${ }^{2}$

The development of oral habit is divided into three periods; sucking period, biting period, and multiple transfer period. ${ }^{8}$ The sucking period develops while the baby is still in the third trimester in its mother's womb. This habit is developed to train the neuromuscular system. This system is the most perfectly developed system found at the time of the birth so that the oral phase of a newborn is well fulfilled.

Oral habits are often found in children with some even starting the habit since the first months of life. According to Christensen and Fields ${ }^{6}$, the oral habits detected in the age of 3-6 years old through a clinical examination is an important issue because after this age, the oral habit is considered as abnormal.

The transition from sucking period to biting period happens in a short period called the transition period. The biting period develops since pre-school age (4-5 years old) and reaches the peak in school age (6-12 years old). Biting habit, especially nail biting, may become the sign of the transition period in a child from the thumb sucking habit previously. This may occur due to a demanding environment that a child has to face when the child is expected to understand his/her responsibility, control his/her childish behavior and follow some rules that may cause the child to feel frustrated and depressed. ${ }^{8}$

The transition period in girls appears when they experience puberty and adolescent phase. This is different from boys who tend to fight back the demands that lead to a longer biting period than the girls. The oral habit is an adaptation mechanism to deal with a tense situation so it cannot be eliminated readily and can only be changed into other habit such as sucking candy, biting pencils, biting lips, tongue and cheek, smoking and bruxism. ${ }^{8}$ Several factors that may cause oral habits are disharmonious relationship between parents and child, unsatisfied oral phase, premature weaning, emotional disturbances, anatomical disorders, and diseases. ${ }^{3}$

\section{Effects of various oral habits in oral cavity of children}

Thumb and finger sucking habit is often found in young children and can be considered as normal during infancy. However, it becomes abnormal if it continues to the end of childhood. Around $2 / 3$ of children who have this habit stop at the age of 5 years old. ${ }^{6}$

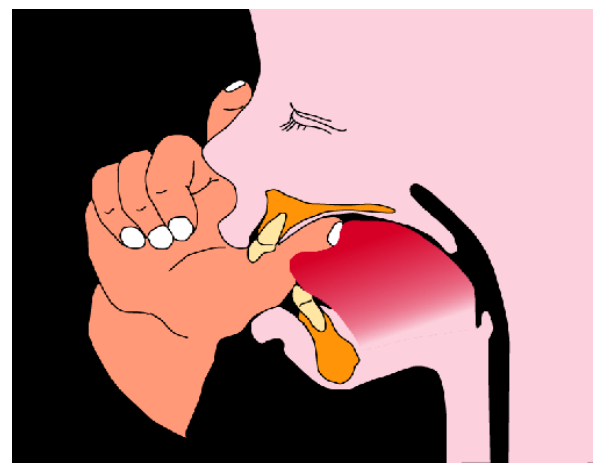

Figure 1. Scheme of finger sucking mechanism that creates abnormal pressure to the dentition and its surrounding soft tissues. $^{9}$
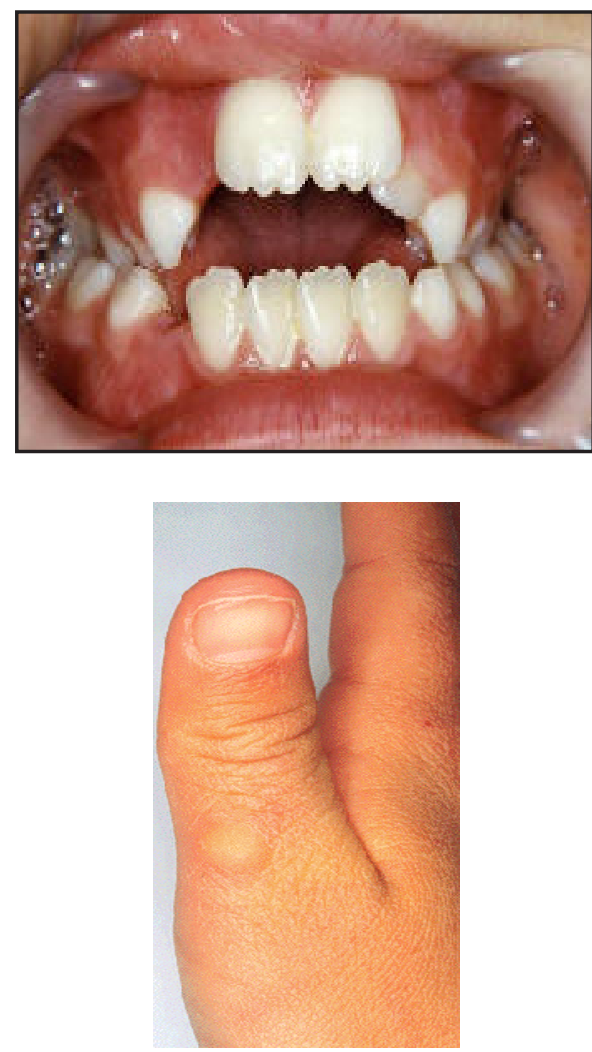

Figure 2. Conditions caused by finger sucking Upper: Clinical condition of anterior open bite and posterior cross bite; Lower: Callus on the thumb. ${ }^{9}$ 


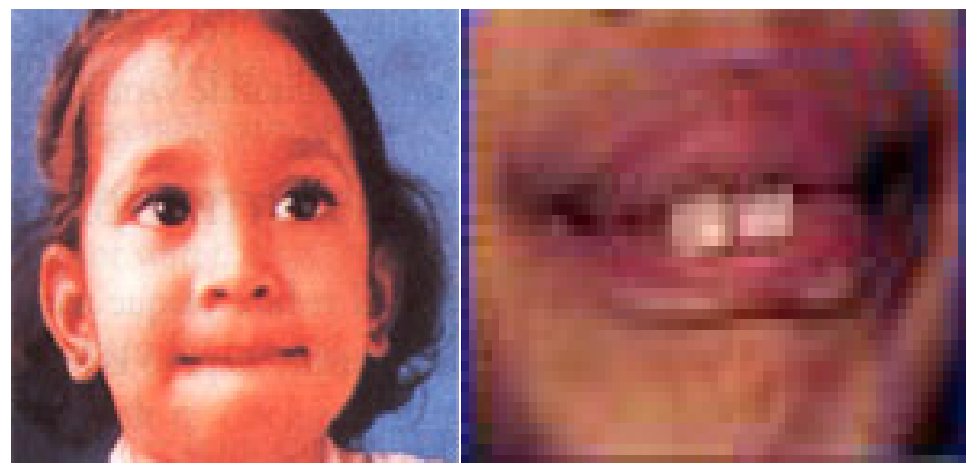

Figure 3. Lip habits. Left: Lip sucking habit; Right: Lip biting habit. ${ }^{9}$

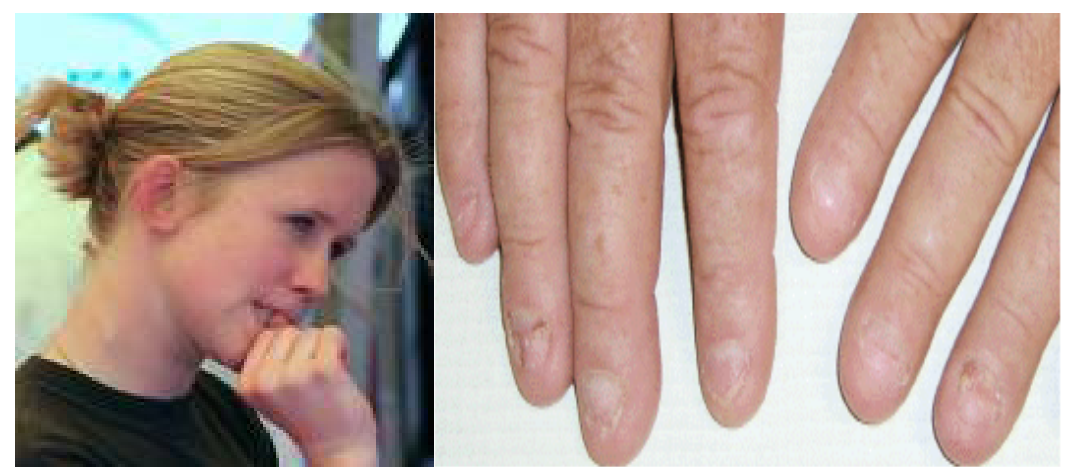

Figure 4. Nail biting habit and the effects. Left: Nail biting; Right: Rough mark on finger nails. ${ }^{9}$

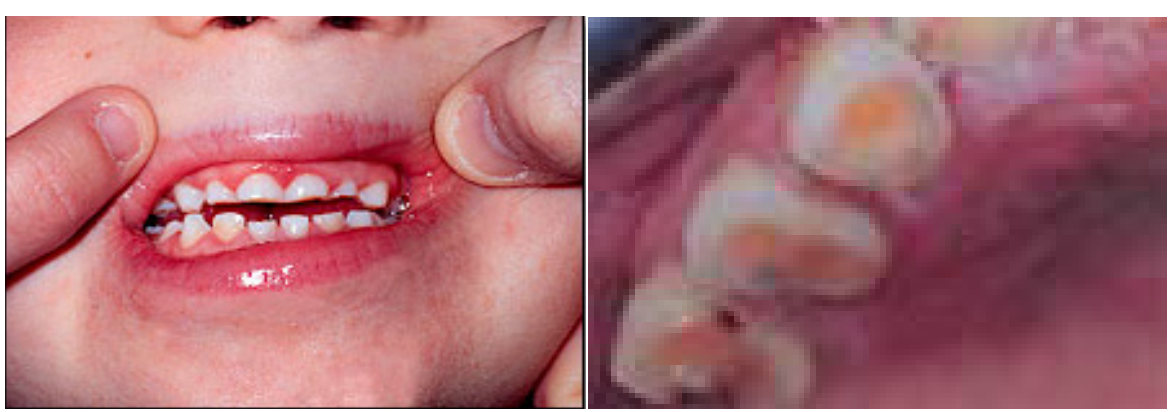

Figure 5. Effects of bruxism. Left: The incisal surface of anterior teeth that experiences attrition; Right: Occlusal condition of the posterior teeth. See the flattened cusps. ${ }^{9}$

Thumb and other finger sucking habit may lead to malocclusion especially when this habit does not stop during the permanent dentition period. The research shows that if this habit is performed 4-6 hours a day it will cause minimum dental movement. However, if a child performs this habit intermittently with a big force, it will not create comprehensive movement. A child who sucks his/her finger continually (more than 6 hours) will experience dental position changes. ${ }^{6}$

Thumb sucking can give different effects compared to other finger sucking. However, the most common effect is that the thumb placed between erupting teeth will create anterior open bite, usually a symmetrical one, which is more apparent on the side that is used to suck the thumb. Open bite tends to be bigger when the tongue is also protrusive. Anterior open bite can also be produced by intrusive incisives or hindered incisive eruption that makes the posterior teeth erupt freely. ${ }^{6}$

The incisive movement towards facial or lingual side depends on the placement of the thumb or the number of finger placed in the mouth. When sucking, the thumb presses the lingual part of the upper incisive to the labial and the labial part of the lower incisive to the lingual (Fig. 1). This may cause additional overjet between the 


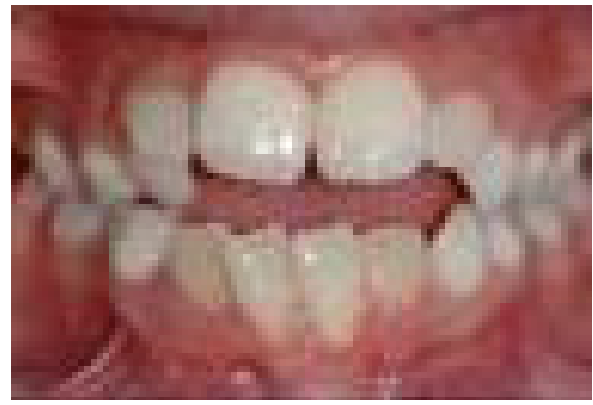

Figure 6. The clinical feature of anterior open bite caused by tongue thrusting. ${ }^{9}$
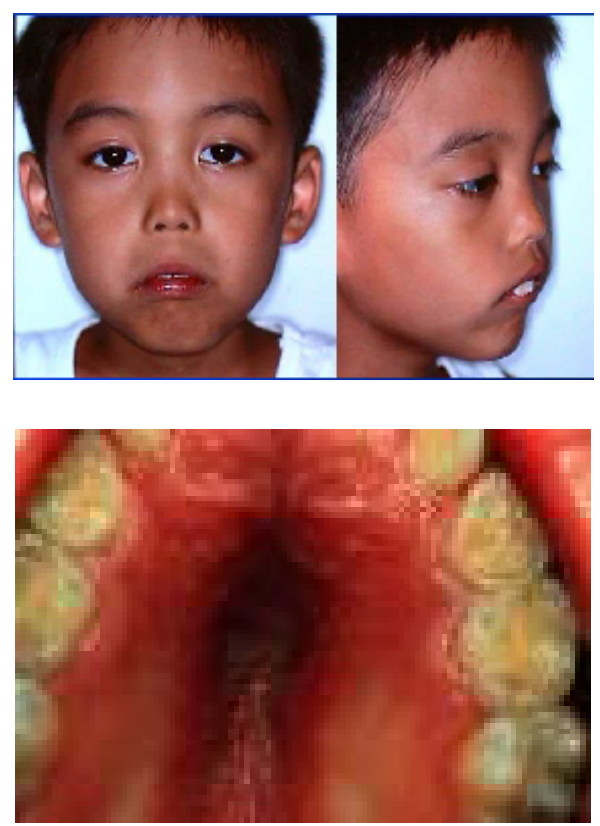

Figure 7. Facial feature of a child (Adenoid faces) and Vshaped palate in a patient who has mouth breathing habit. ${ }^{9}$

upper incisives and the lower incisives. ${ }^{6}$

Finger sucking may cause unilateral posterior crossbite due to a narrowing intraoral pressure and forces from buccal muscle activities. Thumb or other fingers that are sucked between upper and lower incisives may have a hardened skin spot on the finger/callus (Fig. 2). Lip sucking or biting habits are often found simultaneously or as a substitution of finger sucking. This habit may affect the labial and perioral structures (Fig. 3).

A child performs this habit by placing his/ her lower lip to hold the upper incisives. This will create a lingual force from the lower incisives and facial force from the upper incisives. The result is upper incisive protrusion and lower incisive retrusion with bigger overjet. The lower lips can show inflammation signs, reddish appearance with

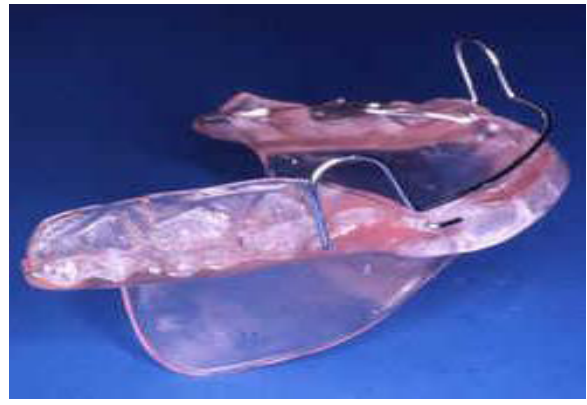

Figure 8. Andresen Activator. ${ }^{8}$

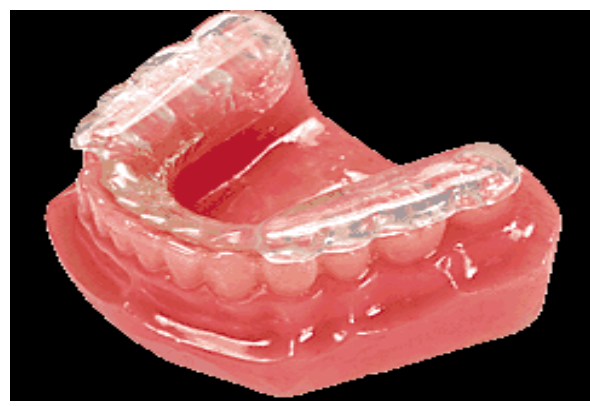

Figure 9. Night Guard. ${ }^{8}$

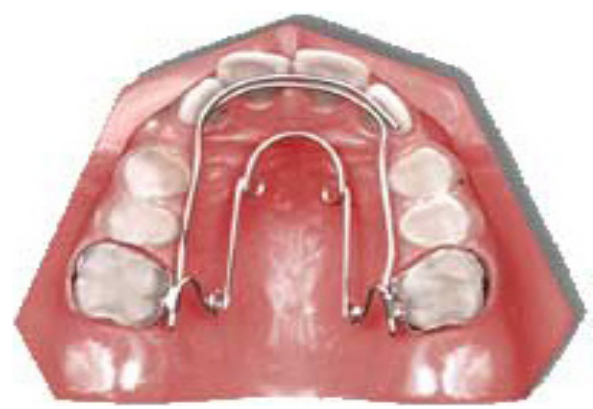

Figure 10. Quad Helix. ${ }^{15}$

teeth marks on it. ${ }^{6}$

Nail biting can also be performed by 3 or 4 year old to 6 year old children. Psychologically, children do this as a reflection of stress, anxiety, fear, high strung or personality maladjustment. The nail biting habit increases during adolescent and reduces in adulthood. ${ }^{6}$

Children who have the habit of nail biting may experience malocclusion although it cannot be ascertained specifically. The conditions that may happen are attrition in anterior dental edges especially in the lower dentition, enamel fracture, crowded anterior teeth, rough marks on the teeth and damaged nail protection (Fig. 4). ${ }^{6}$

Dental grinding habit or bruxism is generally performed by a child during sleep but some children also do it while they are awake. Bruxism 
brings great force to the teeth during grinding that it produces annoying sounds. The friction causes dental surface wear leading to pain caused by loss of enamel layer. If the habit is maintained for quite a long period, the lower anterior teeth will experience attrition and the molar cusps will be flattened (Fig. 5). This will disturb occlusion. The habit may also cause pain in mastication muscles and temporomandibular joint area. ${ }^{10}$

Tongue thrusting habit, especially during swallowing, is an infantile characteristic. A newborn has a relatively big tongue that fill his/ her mouth. The tip of the tongue enters the space between gum pads and, with the lower lip, creates a seal. In the swallowing process, the mandible is controlled by sensory changes between the lips and the tongue. This condition is termed infantile swallow. The tongue position in the swallowing process is different from infantile swallow and with mature/somatic swallow. In the age of 2 to 4 years old, there is a functional balance that is a maturation of the normal development pattern. continued infantile swallow after the age of 4 needs to raise concerns on the possibility of a dysfunction. ${ }^{4}$

A normal swallow is described as a condition where the tongue tip is placed behind the upper incisives and the middle part of the tongue is placed on the palatum durum with the tongue tip creates $45^{\circ}$ angle towards the posterior part of the tongue near the pharynx wall with upper teeth contacting lower teeth and lips contracted in a minimum manner. ${ }^{11}$

Moyers ${ }^{5}$ divides tongue thrust swallowing as the etiology of malocclusion into two types, i.e. simple tongue thrust swallow performed with normally contacted teeth and complex tongue thrust swallow which is performed without dental contact. The simple tongue thrust swallow usually relates to the finger sucking habit and this pattern still persists when the habit has been resolved. The upper incisives are usually protrusive and the swallowing pattern will usually be corrected after the teeth are retraced. The complex tongue thrust swallow is connected with obstructed airway, mouth breathing, tonsillitis, and pharyngitis. The malocclusion description usually includes anterior open bite, big overjet, and sometimes speech disorder is also found (Fig. 6).

Some people have mouth breathing habit that can be due to incompetent mandible or lip postures. However, in the age of 3 to 6 years the incompetent lips can be considered as normal. Another etiology of mouth breathing is obstructed airway in the nose, i.e. nasal turbine and nasopharyngeal adenoid tissue. This may be caused by allergy, atrophy rhinitis, hot and dry weather or polluted air. The presence of anatomic disorders such as bent nasal septum can also obstruct the airway leading to difficulty in breathing to the nose. ${ }^{6}$

A person who has mouth breathing habit is described as having adenoid facies (Fig. 7). The patient usually has a unique posture of open lips, small nose with round end, small and underdeveloped nostril, short upper lips, protrusive incisives, protruding lower lip and no facial expression. The intraoral features include V-shape narrow palate, high palatal curve, protrusive incisives, and Angle Class II occlusion (Fig. 7). ${ }^{3}$ $A$ research by Lowe ${ }^{12}$ shows the intraoral features in a person with mouth breathing habit that include Angle Class II division 1 occlusion, narrow upper dental arch, crowded teeth in the upper and lower arches, vertical growth disturbance, inadequate lip seal, and low positioned tongue that disturb functions. ${ }^{2}$

\section{Oral habit management}

Oral habit management can be performed with or without appliance. The non-appliance management can be performed through psychological approach like giving attention, advice, counseling, reminder system, reward system and medical approach such as medication provision for mouth breathing habit caused by infection or allergy and surgery to correct anatomical disorders and myofunctional therapy, i.e. a therapy to improve oral and facial muscle imbalance as well as abnormal swallowing pattern. This therapy is based on the Triangular Force Concept. ${ }^{11}$

The management using appliance is performed when a child still performs oral habits when he/she is already 6 years old or more or when the permanent teeth start to erupt. The appliance usually used is upper acrylic plate with Adam clasps placed in the two molars to reduce the enjoyment of sucking fingers because fingers cannot touch the palate. Crib is also used to eliminate finger 
sucking and tongue thrusting habit as well as wrong swallowing pattern. ${ }^{3}$ The monoblock functional or Andresen Activator uses the masticatory muscle and mouth closing activities, inhibit anterior growth of upper jaw, induce anterior growth in the lower jaw and pull upper anterior teeth to posterior as well as making it difficult for the child to perform his/her oral habit (Fig. 8). ${ }^{13}$ Oral screen is one of the functional instruments used to manage finger sucking habit and to prevent mouth breathing. Removable Lip Bumper is used to control lip habits such as lip sucking and to improve mentalis muscle hyperactivity. Night guard is used to protect the teeth at night and to prevent bruxing while sleeping (Fig. 9). ${ }^{3}$

The fixed appliance can also be used for this purpose. The appliance may take the form of palatal crib that is made to stop finger sucking habit by preventing finger placement in the mouth. This appliance is usually used for children without posterior crossbite. ${ }^{6}$ Quad Helix is a fixed appliance that is usually used to expand the narrowed palatal curve, improve posterior crossbite and stop finger sucking habit at the same time (Fig. 10). ${ }^{14}$ Rakes can take the form of removable or fixed appliance. This appliance is sharp enough and contains short grill that makes children feel uncomfortable when they put the fingers in the mouth. ${ }^{3}$

\section{DISCUSSION}

Based on a study done by Calisti ${ }^{16}$, finger sucking habit or other oral habits in the higher socioeconomic level is significantly different from those in the middle or lower level. The prevalence of finger sucking in the urban area is higher compared to the rural areas. Parents, especially mothers, from the higher socioeconomic level usually work outside their homes so there is a tendency of not breastfeeding their children optimally. A The child who experience dissatisfaction during the oral phase, especially in breastfeeding, and who has emotional disorder such as loneliness will likely develop oral habits as a means of compensation.

According to Massler ${ }^{8}$, the ages of 6 to 12 year old children are categorized as biting period. Sigmund Freud suggested that the activities which manifested in the mouth is an effort to reduce hunger and is also fun giving satisfaction to the children. ${ }^{1}$ Lip sucking or biting habit is often found simultaneously or as a replacement of finger sucking habit while nail biting is an action that is considered normal after the sucking period. The child does not have any difficulty to perform biting habit because it does not create a social disorder for him. After the age of 12 (adult age), the biting habit may continue on different objects as a replacement of nail biting such as cigarettes, gum, eraser, etc. This may occur in this period when a child is faced with a demanding environment that may create frustration and depression.

According to Graber $^{4}$, the clinical manifestations of oral habits towards occlusion are influenced by the intensity, frequency and duration. The dental position changes will occur if the child continually maintains the habit (more than 6 hours). The impact of oral habits will affect the child dental occlusion development and growth. The malocclusion caused by oral habits has similar clinical features as upper anterior teeth protrusion, anterior open bite, big overjet or Angle Class II malocclusion.

Oral habits may cause malocclusion and may prevent the progress or the success of orthodontic treatment. Therefore, the diagnosis and management of oral habits is necessary especially in children in the developmental period. Strong motivation and behavioral management is also necessary for the child to stop the oral habits. The oral habit case management needs to be performed in the right time and using the right method by considering several influencing factors such as duration, frequency, intensity, age, bone development, teeth and face development, occlusion type and general health. ${ }^{3}$

\section{CONCLUSION}

The conclusion of this paper is that oral habits may cause malocclusion with similar clinical figures as upper anterior teeth protrusion, anterior open bite, big overjet or Angle Class II malocclusion and abnormalities in the perioral structures. In oral habit management, there should be an agreement on the time target without criticizing the child because it will stress the child. Parents or the dentist should emphasize that the therapy is not a punishment for the child. 


\section{REFERENCES}

1. Kartono K. Psikologi anak (Psikologi perkembangan). Bandung: Mandar Maju; 1995.

2. Salzmann. In: Lesmana M. Kebiasaan oral sebagai problema ortodontik. J Ilmiah dan Teknologi Kedokteran Gigi 2003;1(2):15-21.

3. Finn SB. Clinical pedodontics. $4^{\text {th }}$ ed. Philadelphia: WB Saunders Co.; 2003. p. 37085.

4. Graber TM, Rakosi T, Petrovic AG. Dentofacial orthopedice with functional appliances. $2^{\text {nd }}$ ed. St. Louis: Mosby Co.; 1997. p. 19-67.

5. Moyers RE. Handbook of orthodontics. $4^{\text {th }}$ ed. Chicago: Year Book Medical Publisher Inc.; 1988.

6. Friman, et al. In: Pinkham JR, editor. Pediatric dentistry infancy through adolescence. $4^{\text {th }}$ ed. Philadelphia: Elsevier Saunders Co.; 2005. p. 431-9.

7. Dorland WA, Newman. Kamus kedokteran Dorland. $25^{\text {th }}$ ed. Jakarta: Penerbit Buku Kedokteran EGC; 2002.

8. Massler M. Oral habits: Development and management. J Pedodont 1983;7(2):109-19.

9. Palmer B. The importance of breastfeeding as it relates to total health. Kansas City Missouri; 2002. p. 1-18.

10. Mc Donald RE, Avery DR. Dentistry for the child and adolescent. $6^{\text {th }}$ ed. St. Louis: Mosby Co.; 1994. p. 677-706.

11. GarlinerD. Myofunctional therapy. Philadelphia: W.B. Saunders Co.; 1976. p. 3-89.

12. Lowe. In: Mc. Namora Jr. JA, Brudon WL. Orthodontice and dentofacial orthopedics. Ine Ann Arbor Michigan: Needham Press; 2001 p. 112-20.

13. Bishara SE. Textbook of orthodontics. Philadelphia: W.B. Saunders Co.; 2001. p. 24855.

14. Pinkham JR, editor. Pediatric dentistry: Infancy through adolescent. $4^{\text {th }}$ ed. Philadelphia: W.B. Saunders Co.; 2005 p. 366-73.

15. Q.C. Orthodontic Lab. Inc. Habit appliance. 2003 [cited 2007 March 27]. Available from: http://www.qcortho.com.

16. Calisti. In: Koch S, Poulsen S. Pediatric dentistry a clinical approach. Copenhagen: Munksgaard; 2001;321(49):411-9. 